\title{
Direitos humanos e refúgio: uma análise sobre o momento pós-determinação do status de refugiado
}

\author{
Human rights and refugees: an analysis about the moment \\ post-refugee status determination
}

THAIS SILVA MENEZES*

ROSSANA ROCHA REIS**

Rev. Bras. Polít. Int. 56 (1): 144-162 [2013]

\section{Introdução}

O regime internacional dos refugiados contemporâneo tem como fundamento filosófico principal a afirmação de direitos humanos ${ }^{1}$ ocorrida logo após a II Guerra Mundial. Essa vinculação é explorada por diversos autores (Foster 2007; Jubilut 2008; Haddad 2008), os quais notam que a admissão de um refugiado por um Estado materializa o reconhecimento ao indivíduo do direito de deixar seu país de origem (de nacionalidade ou moradia habitual) quando este falha em lhe prover proteção. Tal reconhecimento somente foi possível após ter sido admitido que o indivíduo tem direitos, afirmados historicamente, cuja garantia visa a manter sua vida, segurança e liberdade.

$\mathrm{O}$ instituto do refúgio pode ser definido apontando-se dois momentos: o momento "anterior" ao reconhecimento da condição de refugiado, marcado pelas condiçóes que levam o indivíduo a abandonar o país de origem e que legitimam a utilização desse instituto internacional; e o "posterior", isto é, a vida dessa pessoa no país de acolhida, a fase de proteção.

$\mathrm{Na}$ literatura e no âmbito da política internacional, as discussōes sobre o refúgio frequentemente se concentram em dois pontos: 1) sua existência como questão de interesse internacional - quando se enfatiza sua justificativa filosófica e histórica; 2) sua relação com o sistema internacional - quando se evidenciam os desafios para sua manutenção enquanto instituto de proteção internacional. Em ambos os casos, a análise comumente trata da questão dos direitos humanos, restringindo-se, porém, ao momento "anterior" à determinação da condição de refugiado.

\footnotetext{
* Doutoranda em Relações Internacionais da Universidade de Brasília (UnB) (thaissilvamenezes@hotmail.com).

** Professora do Instituto de Relaçóes Internacionais da Universidade de São Paulo (USP) (rossanarr@uol.com.br).

1 Processo, ao longo da história, de elaboração e expansão do entendimento sobre direitos que devem ser reconhecidos aos indivíduos devido à sua condição de ser humano (Comparato 2010).
} 
No que concerne à vida dos refugiados em seus países de acolhida, os debates sobre direitos humanos e refúgio frequentemente se limitam a demonstrar como os direitos humanos desses indivíduos vêm sendo desrespeitados nesse ambiente enfatizando o fato de que a maior parte dos refugiados se encontra em países pobres e reafirmando a constatação (embora não se aprofundem na questão) de que a prerrogativa da soberania estatal possibilita o provimento de respostas insatisfatórias para a problemática. Tais abordagens têm, dessa forma, caráter predominantemente descritivo.

Este artigo difere, assim, de outros trabalhos realizados, por buscar ir além da abordagem descritiva da relação entre direitos humanos e refúgio no momento após a determinação do status de refugiado. Ao se admitir que os direitos humanos compõem a justificativa para a determinação da condição de refugiado - seja somente devido à aproximação filosófica ou por entender que a violação de direitos humanos é sempre um fator que legitima o emprego desse instituto -, compreendese, por conseguinte, ser essencial pensar a proteção ao indivíduo também sob o prisma dos direitos humanos. Dessa forma, utiliza-se a ideia de direitos humanos como parâmetro para discutir a proteção no país de acolhida, visando a tecer reflexôes sobre os aspectos que configuram o modo como essa proteção é, de fato, concretizada. Isso significa estabelecer um olhar sobre a questão considerando a estrutura mais ampla das relações internacionais.

Dada a lacuna de trabalhos no sentido proposto, elabora-se uma análise seminal sobre como o Alto Comissariado das Nações Unidas para os Refugiados $(\mathrm{ACNUR})^{2}$ - mais importante organismo de trato da questão dos refugiados, que admite ter suas origens nos direitos humanos e que seu trabalho envolve a promoção e o respeito a eles - se manifesta em relação aos direitos humanos nas publicações que versam sobre os refugiados em seus países de acolhida - fomentando reflexões sobre motivos e consequências da atuação dessa organização.

Duas publicações servirão de subsídio à análise: os Anuários estatísticos, que trazem a situação geral dos refugiados no mundo a cada ano; e os Apelos globais, publicações anuais que visam a angariar recursos para a atuação do ACNUR em cada Estado, destacando as necessidades para a proteção que o ambiente específico do país coloca. Dada a impossibilidade - para este artigo - do exame das condições do refúgio em cada país abarcado pelos Apelos globais, tomam-se como referência as publicações concernentes ao Irã, ao Quênia e à Alemanha, países vinculados ao regime internacional dos refugiados e que estão entre os países com maior número de refugiados reconhecidos ${ }^{3}$.

2 Doravante também denominado ACNUR, Escritório ou Agência.

3 Os países com maior número de refugiados reconhecidos são: Paquistão, Irã, Síria, Alemanha, Jordânia, Quênia, Chade, China, Estados Unidos e Gră-Bretanha (UNHCR 2011). Não analisamos no artigo as publicações sobre Paquistão, Síria e Jordânia porque esses países, embora abriguem maior número de refugiados, não aderiram à Convenção Relativa ao Estatuto de Refugiado, de 1951 - o que representaria concordância com os princípios e propósitos do regime internacional dos refugiados, o qual se funda nesse documento. Logo, não é possível utilizá-los como referência para uma análise que se baseia em parâmetros não reconhecidos, ao menos oficialmente, por esses Estados. 
Objetivando uma análise atual sobre como a questão dos direitos humanos tem aparecido na agenda sobre refugiados - no que toca ao momento posterior ao reconhecimento do status e focando o ACNUR -, serão consideradas as publicações que versam sobre os últimos dez anos, de 2002 a 2011. Esse período histórico é relevante, também, por coincidir com o desenvolvimento da iniciativa Consultas globais do ACNUR, a qual consistiu de uma série de conferências, realizadas entre 2001 e 2002, com diversos atores de interesse, objetivando reafirmar o comprometimento dos Estados com a implementação da Convenção Relativa ao Estatuto do Refugiado ${ }^{4}$, de 1951, avaliar os desenvolvimentos do Direito Internacional dos Refugiados e tratar das questóes não abarcadas pela Convenção (UNHCR 2001b). Acredita-se que por meio de tal programa foi possível mapear características e desafios contemporâneos e, assim, prover informaçóes para a atuação do ACNUR e para sua subsequente postura, até mesmo no que diz respeito à temática dos direitos humanos dos refugiados.

Estrutura-se a análise tratando brevemente como o ACNUR se manifesta sobre a vinculação entre direitos humanos e refúgio no que se refere ao reconhecimento do status de refugiado e à proteção "em" países de acolhida - quando o ACNUR trata da proteção de uma forma geral, sem considerar Estados específicos. Em seguida, como foco do estudo, analisa-se como o ACNUR se expressa no que concerne à proteção "nos" países de acolhida.

\section{ACNUR e direitos humanos: o reconhecimento do status de refugiado e a proteção "em" países de acolhida}

Nos últimos anos (principalmente a partir da década de 1990), a vinculação entre refúgio e violação de direitos humanos tem sido fortemente sustentada pelo ACNUR. Um ponto chave para o entendimento dessa relação refere-se ao significado de "perseguição". A Agência sustenta que uma ameaça à vida ou à liberdade por motivos de raça, religião, nacionalidade, opinião política ou pertencimento a grupo social é sempre perseguição. Outras sérias violações de direitos humanos - pelas mesmas razões - também constituiriam perseguição, a depender das circunstâncias específicas (UNHCR 1992). Ademais, segundo o Escritório, decidir que um indivíduo tem "fundado temor de perseguição" é, de fato, concluir que um (ou mais) de seus direitos humanos não está sendo respeitado (UNHCR 1995). Em alguns textos, o ACNUR não somente declarou que a violação de direitos humanos leva ao fluxo de refugiados, como sustentou que essa é a maior causa desses movimentos (UNHCR 1995, 1997) e se definiu como uma organização de direitos humanos (UNHCR 1995, 1997). Enfim, é amplamente reconhecido pelo Escritório que refúgio e direitos humanos são intrinsecamente vinculados e que a violação desses direitos legitima o reconhecimento do status de refugiado.

4 Também denominada ao longo do texto "Convenção de 1951" ou apenas "Convenção". 
O ACNUR, todavia, reconheceu a ligação entre direitos humanos e o refúgio não somente no que se refere à definição de refugiado, como também à vida do refugiado em seu país de acolhida. O Escritório tem sustentado que a proteção é sua função principal, a qual abarca todas as atividades que buscam restabelecer a dignidade dos refugiados, protegendo seus direitos e buscando soluçóes duradouras dentro da estrutura de diversos tratados de direitos humanos (UNHCR 2005a). Para o ACNUR, a proteção não pode se distanciar dos direitos humanos, não apenas porque a condição de refugiado existe devido a uma violação específica de direitos humanos, mas também em razão de três outras questôes:

a) O refugiado é, antes de qualquer condição, um ser humano, ao qual diversos direitos foram reconhecidos internacionalmente. Os requerentes de refúgio ${ }^{5}$ e os refugiados se "[...] beneficiam dos direitos e liberdades fundamentais reconhecidos nos instrumentos internacionais de direitos humanos. A protecção do refugiado deve, nessa medida, ser vista no contexto mais vasto da protecção dos direitos humanos." (ACNUR e ONU 2002, 14).

b) A Convenção de 1951, que estabelece o conceito de refugiado e é a principal referência para o regime, tem como fundamento a afirmação internacional de direitos humanos. A Agência declara que os direitos humanos são a fonte primária dos princípios e estruturas existentes para a proteção dos refugiados (UNHCR 1998). Ademais, o ACNUR entende que, como uma agência das Naçóes Unidas, deve assegurar que os direitos humanos de seus beneficiários sejam mantidos (UNHCR 1997, 1995).

c) A própria Convenção enuncia direitos a serem observados em relação aos refugiados. Ressalta-se que a proteção aos refugiados opera dentro de uma estrutura de direitos e deveres individuais e responsabilidades estatais (UNHCR 1998). Sustenta-se que, quando reconhecidos como refugiados, há a aplicação a esses indivíduos de um regime legal especial que estabelece direitos e determina assistência e medidas de proteção, os quais, em conjunto, constituem o que é conhecido como "proteção internacional ao refugiado" (UNHCR 2005b).

Com base em tais consideraçóes, entende-se que o respeito aos direitos humanos é essencial para a proteção dos refugiados (UNHCR 1995). Nesse sentido, as ações do ACNUR são firmemente baseadas e guiadas por princípios universais de proteção ao refugiado e por padrões de direitos humanos, que

5 No texto original, a expressão utilizada é "requerentes de asilo". Na atualidade, os termos "asilo" e "refúgio" ora são utilizados como sinônimos (na maioria dos casos), ora denotam institutos diferentes (âmbito latinoamericano), sendo a distinção principal ser o "refúgio" um instituto internacionalmente estabelecido e o "asilo" uma expressão da discricionariedade estatal. Uma vez que este texto trata somente do instituto internacionalmente reconhecido - que tem como referência a Convenção de 1951 -, utiliza-se o termo "refúgio". Para discussão a respeito das diferenças entre "refúgio" e "asilo", vide Barreto (2006) e Jubilut (2007). 
reforçam a legitimidade dessas ações e são essenciais para o alcance da segurança desses indivíduos (UNHCR 1998).

Nesse contexto de reconhecimento da importância fundamental das questôes de direitos humanos, o ACNUR vem manifestando sua preocupação em relação ao desrespeito aos direitos humanos dos refugiados. A autossuficiência é sempre destacada como meio necessário para se concretizar a proteção ao refugiado, e somente pode ser atingida dentro de uma estrutura de direitos civis, sociais e econômicos (UNHCR 2005a). O ACNUR também destaca os casos em que solicitantes e refugiados são detidos ou enviados à força para zonas onde sua vida, liberdade e segurança estão ameaçadas (ACNUR e ONU 2002). Em alguns casos, a esses indivíduos em centros de detenção é negado o acesso a tribunais e à assistência judiciária (ACNUR e ONU 2002). Salienta-se, também, que violações à integridade física de solicitantes e refugiados têm ocorrido após a entrada no país de refúgio (UNHCR 1998).

Igualmente, a Agência preocupa-se com o aumento da intolerância e das agressões que afetam os solicitantes de refúgio e os refugiados (ACNUR e ONU 2002) e com a impossibilidade de alguns refugiados de obter trabalho, possuir seu próprio negócio e comprar terrenos (o que remonta à necessidade de autossuficiência para a proteção integral, a qual somente é possível em uma estrutura de direitos garantidos). Em tais situações, embora não sejam expulsos fisicamente à força, os refugiados podem sentir-se obrigados a partir devido às condições de vida degradantes a que são submetidos nos países de acolhimento.

\section{ACNUR e direitos humanos: a proteção "nos" países de acolhida}

A Agência admite, portanto, a vinculação entre direitos humanos e refugiados no que concerne ao momento "anterior" ao reconhecimento do status de refugiado - entendendo que a violação de direitos humanos se encontra no cerne das razões que forçam o indivíduo a deixar seu país; e no "posterior" à declaração do status - sendo a garantia dos direitos humanos essencial para a concretização da proteção no país de acolhida. Tendo isso em mente, passa-se à observação das publicações do $\mathrm{ACNUR}^{6}$ sobre o refúgio no mundo para identificar em quais circunstâncias se utiliza a expressão "direitos humanos" (human rights).

\section{Anuários estatísticos}

A mais relevante constatação quando se analisam os anuários estatísticos do ACNUR de 2001 a 2010 é que a ideia de "direitos humanos" é pouco clamada

6 Os Anuários versam sobre o refúgio em determinado ano; por esse motivo, são divulgados posteriormente ao ano tratado. Já os Apelos buscam angariar fundos para as atividades do ACNUR no ano em questão, isto é, no Apelo Global 2002 são divulgados os objetivos e estratégias para 2002 e trata-se dos desenvolvimentos ocorridos no ano anterior. Por esse motivo, consideram-se os Anuários de 2001 a 2010 e os Apelos globais de 2002 a 2011. 
pela Agência. Nos Anuários de 2001 a 2004, não se menciona a expressão "direitos humanos" e na publicação sobre 2005 o mesmo é utilizado uma única vez, quando o ACNUR declara que um desafio central para a proteção internacional é assegurar a admissão, a estadia e o respeito do Estado de refúgio a "direitos humanos" básicos (UNHCR 2007a).

O Anuário sobre 2006 (UNHCR 2007b) é aquele em que mais está presente a expressão "direitos humanos". A publicação conceitua os deslocados internos como pessoas forçadas a deixar seus locais de origem, como resultado (entre outros possíveis fatores) de violaçôes de "direitos humanos". Ademais, define refugiados como as pessoas reconhecidas pela Convenção de 1951, pelo Protocolo de 1967, pela Convenção da Organização da Unidade Africana de 1969, pelo Estatuto do ACNUR e pelas pessoas às quais foram garantidas formas complementares de proteção ou proteção temporária. Tais formas complementares são mecanismos para tratar as necessidades de proteção dos refugiados que não se encaixam na definição da Convenção, caso interpretada em sentido estrito, e podem ser fundamentados nas obrigações do país derivadas do Direito Internacional dos "Direitos Humanos" ou de provisões nacionais. Os "direitos humanos" também aparecem em relação ao reassentamento, ao se sustentar que este é adequado à proteção de refugiados cuja vida, liberdade, segurança, saúde ou outros "direitos humanos” fundamentais estão em risco no país de refúgio. Declara-se, também, que a maioria dos fluxos de refugiados resulta de guerras ou graves violaçôes de "direitos humanos". Por fim, o ACNUR identifica a necessidade de treinamento para as autoridades locais sobre os princípios da proteção aos refugiados, do Direito Humanitário e dos "Direitos Humanos" para melhorar a governança da questão em alguns países.

No Anuário de 2007 (UNHCR 2008a), o ACNUR enfatiza sua atuação para a determinação do status de refugiado em regiōes com fluxos forçados originados de países que têm "histórico pobre de direitos humanos" e, em relação às crianças, destaca que as desacompanhadas e separadas têm direito à proteção sob, entre outros instrumentos, o Direito Internacional dos "Direitos Humanos". Sobre 2008 (UNHCR 2009), afirma que a proteção inclui o usufruto de "direitos humanos” e melhor segurança e integridade física. Já no que diz respeito a 2009 (UNHCR 2010), ressalta que a responsabilidade dos países de acolhimento de determinar se um solicitante é refugiado é frequentemente incorporada à legislação nacional e deriva da Convenção de 1951 e de outros instrumentos de "direitos humanos". Também declara que a falta de acesso a trabalho e os abusos de "direitos humanos" pelas autoridades levam a deslocamentos secundários (saída do país em que primeiramente se buscou asilo). O Anuário de 2010 não traz nenhuma nova menção à questão dos direitos humanos.

Portanto, as publicações raramente utilizam a ideia de "direitos humanos" para se expressar em relação ao estado do refúgio no mundo. As poucas vezes em que tal signo é aludido se referem, majoritariamente, à proteção de uma forma geral è̀ 
violação de direitos humanos como motivo que leva ao fluxo forçado. Em algumas ocasiōes, também se mencionam os instrumentos de direitos humanos como fonte da responsabilidade estatal para com os refugiados ou como o conhecimento necessário para concretização da proteção. Somente em uma passagem, no Anuário de 2009, o ACNUR identifica os abusos de direitos humanos que ocorrem em países de acolhida como obstáculos à proteção e geradores da necessidade da busca por proteção em outro território.

Uma segunda constatação é que o ACNUR em algumas (poucas) passagens dos textos se expressa utilizando o termo "direitos" (rights). Nesses casos, trata-se principalmente de três questões: reassentamento, integração local e crianças. É frequente nos Anuários a afirmação de que os refugiados reassentados normalmente têm acesso a um conjunto de "direitos" sociais, econômicos e legais (UNHCR 2005c, 2006a, 2007a, 2007b). Em relação à integração local, sustenta-se que por meio dessa solução são providos aos refugiados pelo país de acolhida "direitos" amplamente proporcionais àqueles desfrutados pelos cidadãos (UNHCR 2005c, 2006a, 2007a). Também afirma-se que a integração econômica nesses países envolve o acesso aos "direitos" sociais e econômicos presentes na Convenção de 1951, o que inclui o "direito" a buscar meios de sobrevivência sustentáveis e se engajar em atividades de geração de renda (UNHCR 2005c, 2006a, 2007a). No que concerne às crianças, ressalta-se a necessidade de se garantir seu "direito" à educação (UNHCR 2007a, 2007b, 2008a) e que o ato de se registrar uma criança é um meio de se assegurar seus "direitos", como acesso a saúde e educação, proteção e limite etário legal para emprego e recrutamento militar (UNHCR 2007b, 2011).

O signo dos "direitos" também aparece pontualmente em relação a outras questóes, como à importância do registro para os refugiados, por possibilitar acesso a "direitos" básicos (UNHCR 2010a); a questôes de gênero, salientando a necessidade de se assegurar o usufruto de "direitos" a todos os refugiados - mulheres e homens (UNHCR 2007b, 2011); ao "direito" ao trabalho (UNHCR 2008a); e ao "direito" de asilo7 (UNHCR 2008a).

\section{Apelos globais}

Como justificado na introdução, utilizam-se como referências as publicações concernentes ao Irã, ao Quênia e à Alemanha - que figuram entre os países com maior número de refugiados reconhecidos e se vinculam de uma forma mais integral ao regime internacional dos refugiados. Também nessas publicaçōes, buscou-se identificar as passagens em que o ACNUR se manifesta usando os termos "direitos humanos" (human rights) e "direitos" (rights).

7 Nesse caso, ao contrário do descrito na nota 5, manteve-se o termo "asilo" porque se faz referência ao amplamente conhecido "direito de asilo" disposto no artigo 14 da Declaração Universal de Direitos Humanos de 1948 e do qual deriva o instituto do refúgio, como explicado por Jubilut (2007). 
Irã

Nas publicações examinadas, em nenhum momento o ACNUR se refere a "direitos humanos" quando trata das questões de refúgio no Irã. Já o termo "direitos" aparece em algumas passagens dos textos. O ACNUR menciona "direitos" ao incluir entre seus principais objetivos o fomento à implementação da legislação sobre os "direitos" dos estrangeiros - e ao determinar como propósito o apoio ao governo para o planejamento de uma estrutura legal que garanta aos refugiados o "direito" ao trabalho e o acesso à saúde e à educação (UNHCR 2002b). A Agência determina como uma de suas estratégias a cooperação com o governo para estabelecer um procedimento nacional para determinação do status de refugiado construído em torno de um conjunto de "direitos" e obrigações atrelado a essa condição (UNHCR 2004b). Também afirma que os afegãos deportados terão o "direito" de apresentar uma reivindicação por proteção continuada no Irã e de tê-la determinada de acordo com padrōes internacionais.

O Escritório também estabelece como um dos objetivos centrais o aumento da proteção de solicitantes e refugiados por meio do monitoramento e promoção do respeito a seus "direitos" (UNHCR 2005d), ressaltando que os refugiados nesse país não têm o "direito" legal a trabalho assalariado. Do mesmo modo, destaca a recusa do governo em garantir ao próprio ACNUR o "direito" de determinar o status de refugiado a solicitantes individuais, o que complica a estrutura de proteção do país (UNHCR 2006b).

Também afirma-se que serão feitas novas negociações com o governo iraniano para que este continue a assegurar refúgio a refugiados registrados e seu acesso a "direitos" e serviços (UNHCR 2008). Nos Apelos para 2010 e 2011, o termo "direitos" é utilizado apenas quando se distinguem os "grupos de direitos e objetivos" para estabelecer a previsão de orçamento.

\section{Quênia}

Nas publicações que visam a estabelecer o orçamento para as operações no Quênia, alude-se a "direitos humanos" em dois momentos: quando a Agência afirma que aumentará o entendimento do governo sobre relevantes instrumentos de "direitos humanos" (UNHCR 2002b) e quando relata a chegada de refugiados escapando de violência e violações de "direitos humanos" (UNHCR 2009b).

Sobre "direitos", o ACNUR assevera que consultas lhe estão sendo realizadas pelo governo sobre os componentes relacionados a "direitos" da Carta dos Refugiados (Refugee Bill) (UNHCR 2003). É declarado que em 2010 foi adotada uma nova constituição, a qual reconhece os "direitos" das pessoas de interesse do ACNUR (UNHCR 2010b). Para 2010, um dos objetivos é a promoção de melhor acesso a serviços públicos e outros "direitos", como o "direito" ao trabalho e à naturalização, para refugiados urbanos (UNHCR 2009b). Para 2011, destaca-se 
como estratégia o trabalho junto ao governo queniano para assegurar os "direitos" dos refugiados (UNHCR 2010b).

\section{Alemanha}

As publicaçōes sobre a Alemanha apresentam uma diferença relevante em relação àquelas sobre o Irã e o Quênia: não há uma publicação específica buscando levantar fundos para as atividades do ACNUR especificamente em seu território. Os Apelos globais da Europa geralmente são divididos por áreas geográficas, não tratando dos países individualmente, mas dando um panorama geral da situação dos refugiados nas sub-regiōes ${ }^{8}$.

As publicaçōes referentes aos anos de 2002, 2003 e 2006 a 2010 simplesmente não mencionam "direitos humanos", ou mesmo "direitos". Traçando prospecçôes para 2004, estabelece-se como objetivo estratégico a manutenção da equivalência dos sistemas de acolhimento na Europa com os princípios do Direito Internacional dos "Direitos Humanos". O ACNUR ainda expressou sua preocupação com os padrôes desapontadores estabelecidos pela harmonização resultante das diretivas europeias sobre refúgio, as quais, em alguns casos, falham em conformar com princípios do Direito Internacional dos "Direitos Humanos" (UNHCR 2003). A Agência afirma, ainda, trabalhar com os países para desenvolver medidas de manejo e controle de migração que respeitem integramente o "direito" de buscar refúgio (UNHCR 2003; 2004b). Em relação a 2011, a única menção a "direitos" refere-se ao futuro fortalecimento da análise do Escritório sobre o perfil e os "direitos" de não cidadãos (UNHCR 2010b).

A descrição acima sobre como os termos "direitos humanos"/"direitos" aparecem nas publicaçôes analisadas - juntamente com o exame de outros documentos do ACNUR que tratam da proteção internacional - leva-nos a uma conclusão: no que se refere à proteção "em" países de acolhida, ou seja, à proteção de modo geral, o ACNUR tem reafirmado a necessidade de uma perspectiva de direitos humanos para que ela seja realizada de acordo com seus objetivos; já no que concerne à descrição e análise sobre o ambiente em que o refúgio se concretiza, ou seja, quando se trata da proteção "nos" países de acolhida aqui apresentados, frequentemente a Agência não se expressa em termos de "direitos humanos". O estudo empreendido constata, assim, que o ACNUR pouco alude à ideia de "direitos humanos" e que, se em alguns momentos faz referência a "direitos", também não se pode sustentar que essa é uma palavra de uso recorrente na literatura examinada, principalmente para tratar da situação de vida dos refugiados nos países de acolhida? .

8 Os Apelos entre 2002 e 2009 que tratam da Alemanha referem-se a toda a Europa Ocidental; já aqueles para os anos de 2010 e 2011 abarcam, numa mesma publicação, além da Europa Ocidental, o norte e o sul da Europa.

9 É necessário destacar que especificamente nos Anuários foi crescente a utilização da expressão "direitos humanos" ao longo dos anos - porém, continuou, predominantemente, relacionada ao momento "anterior" à determinação do status de refugiado. 
Outra questão à qual deve ser dado destaque se relaciona ao fato de que, na maioria dos casos em que se mencionam "direitos", não é evidente se a intenção é se referir aos direitos legalmente reconhecidos no país, aos direitos declarados especificamente na Convenção ou aos "direitos humanos" reconhecidos em diversos instrumentos internacionais e que servem de base para a existência e concretização dos objetivos do regime. Essa pluralidade de entendimentos possíveis torna-se ainda mais evidente quando o ACNUR afirma que o governo iraniano se recusa a garanti-lhe o "direito" de determinar o status de refugiado (UNHCR 2006b) apontando para uma atribuição legal a ser estabelecida pelo Estado à Agência, mas também denominada "direito".

Nas publicaçōes analisadas, a ideia de "direitos humanos" é pouco invocada e quando o é, se refere, preponderantemente, às violações que levam os indivíduos à fuga, ou seja, à vinculação entre direitos humanos e refúgio no momento anterior ao reconhecimento da condição de refugiado (e como justificativa para tal). Em algumas outras poucas vezes, alude-se à necessidade de ampliação do conhecimento das autoridades sobre os direitos humanos. Assim, a noção de "direitos humanos" é mais frequentemente invocada quando o Escritório aborda a questão de maneira ampla, sem se referir a um país específico de refúgio: quando se afirma que um desafio central para a proteção internacional é assegurar a admissão, o refúgio e o respeito do Estado por "direitos humanos" básicos (UNHCR 2007a); ao sustentar que a proteção inclui o usufruto de "direitos humanos" (UNHCR 2009a); e quando se assevera que abusos de "direitos humanos" pelas autoridades dos países de acolhida levam a movimentos secundários de refugiados (UNHCR 2010a).

Outras observações merecem destaque: nas publicações sobre o Irã, em momento algum se fala em "direitos humanos" e, nas publicações sobre a Europa Ocidental, esses somente são mencionados ao se apontar a necessidade de criação de sistemas de refúgio cujos princípios sejam equivalentes aos do Direito Internacional dos "Direitos Humanos". No caso do Quênia, a expressão também não é empregada no tocante ao ambiente de refúgio, somente no que concerne aos motivos que levam ao fluxo para seu território e à necessidade de melhor familiaridade do governo com a área dos "direitos humanos". Tais constatações levam ao questionamento: inexistem, são efêmeros ou de baixa intensidade os problemas vinculados ao desrespeito aos direitos humanos dos refugiados ${ }^{10}$ ?

A resposta para a pergunta é "não". Mesmo não se utilizando do signo dos "direitos humanos", os problemas vinculados ao desrespeito aos direitos humanos dos refugiados nos seus países de acolhida estão presentes nessas publicações, principalmente nos Apelos globais. Em relação ao Irã, o ACNUR destaca sempre como objetivo assegurar a proteção efetiva dos refugiados. Fala-se em alcançar condições de vida que sigam padrōes satisfatórios. Ou seja, é descrita uma situação

10 Rubio (2010) afirma que foi estabelecida uma concepção pós-violatória dos direitos humanos. Devido a essa concepção, os direitos humanos somente são aludidos em caso de violação, o que significa que nas circunstâncias em que não há violação dificilmente a noção de "direitos humanos" será ressaltada. 
em que os padrões de vida não são "satisfatórios" e a proteção não vem se realizando de forma efetiva. Algumas afirmações específicas discriminam melhor a situação: problemas relacionados ao acesso à educação e à saúde; o trabalho sendo vinculado a uma licença e restrito a algumas áreas de atuação; além da imposição de taxas municipais aos refugiados. O ACNUR afirma que muitos refugiados vivem sob condições socioeconômicas difíceis (UNHCR 2008b) e a autossuficiência é colocada a cada ano como um dos principais objetivos alvejados pela Agência.

Os refugiados no Irã sofrem, ainda, com outras graves restrições a seus direitos. A liberdade de movimento dos refugiados tem sido limitada, pois aos refugiados não é permitido moradia em determinadas províncias ou regiôes (UNHCR 2007c); centenas de afegãos têm sido submetidos a prisão, detenção e deportação e há relatos de refugiados registrados entre estes (UNHCR 2006b); a imposição de taxas municipais aos refugiados afegãos viola o artigo 29 da Convenção de 1951 e existe uma distinção evidente no trato direcionado a refugiados afegãos e iraquianos (UNHCR 2007c). No caso da liberdade de movimento, assim como no que se refere ao trabalho remunerado, de fato, o Irã não age em contraposição às obrigações derivadas da Convenção, pois esse país a adotou com reservas aos artigos 17, 23, 24 e 26. O mesmo, todavia, não pode ser afirmado no que diz respeito às prisões, deportações e imposição de taxas municipais. Constatam-se, portanto, violações de princípios básicos da proteção internacional como o nonrefoulement ${ }^{11}$, além de violações à liberdade de movimento e à liberdade de forma geral - fatos que colocam em risco a vida, liberdade e segurança desses indivíduos.

A situação dos refugiados no Quênia é ainda mais grave. A situação nas áreas de educação, distribuição de comida, provisão de abrigo e cuidados médicos permanece abaixo de padrōes mínimos aceitáveis (UNCHR 2003). O ACNUR estabelece sempre como meta prover serviços necessários para que se preservem padrōes "mínimos" de vida e acesso a serviços essenciais. Nesse sentido, são assustadoras as afirmaçōes como "O ACNUR buscará atingir padrōes 'mínimos' de assistência humanitária pelo menos na proteção e nas atividades de salvamento e manutenção da vida." (UNHCR 2004b). A taxa de má-nutrição aguda global permanece em 12\% nos campos (UNHCR 2010b). Nos campos de Dadaab, apenas $17 \%$ dos refugiados vivem em habitação adequada (UNHCR 2010b).

No Quênia, o cerne da política para os refugiados é a concretização da restrição à sua liberdade de movimento: a política de encampamento. Os refugiados são forçados a viver em locais com clima quente e seco, com recursos naturais limitados, não podendo cultivar a terra ou buscar emprego fora dos campos (UNHCR 2002b); assim, são completamente dependentes do ACNUR para proteção e assistência material. Ademais, a maior parte (75\%) não tem documentação (UNHCR 2009b), a situação de segurança dentro e no entorno dos campos é precária (UNHCR 2002b)

11 "Nenhum dos Estados Contratantes expulsará ou rechaçará, de forma alguma, um refugiado para as fronteiras dos territórios em que sua vida ou liberdade seja ameaçada em decorrência de sua raça, religião, nacionalidade, grupo social a que pertença ou opiniōes políticas." (ONU 1951, art. 33). 
e há uma hostilidade entre os refugiados e as comunidades receptoras que pode facilmente explodir em violência, colocando suas vidas em risco (UNHCR 2002b). Além disso, em janeiro de 2007, as autoridades quenianas fecharam a fronteira com a Somália, motivo pelo qual, embora alguns tenham conseguido acessar o Quênia, somalis foram privados de buscar refúgio nesse território (UNHCR 2007c).

Para a região que abarca a Alemanha, o ACNUR destaca a preocupação com a necessidade de se manter a qualidade do refúgio e o acesso ao território, pois aumentam as medidas restritivas ao acesso a esses países, de modo que os refugiados podem ser privados de buscar proteção nesses Estados. Outros problemas, sempre mencionados nas publicações do ACNUR, dizem respeito à detenção de solicitantes de refúgio, a qual frequentemente ocorre em instalaçôes subpadronizadas (UNHCR 2008b) - uma clara violação à liberdade e à segurança do indivíduo com necessidade de proteção internacional. Outra problemática repetidamente destacada relaciona-se à questão da xenofobia, do racismo e da intolerância, que representa um dos principais desafios para a proteção ao refugiado na região (UNHCR 2005d), além de ser um grande empecilho para a integração deles em seus países de refúgio e, assim, para o usufruto de direitos.

Logo, observa-se que princípios básicos, como o non-refoulement - e, consequentemente, o direito à vida -, estão sendo violados nos países em questão. Diversas violações de direitos humanos, algumas análogas àquelas que levam ao reconhecimento da necessidade internacional de proteção, como as que afetam o direito à liberdade e à segurança, são verificadas nos países de acolhida. Essas afirmações decorrem da análise das publicações do ACNUR apresentadas em nosso trabalho; contudo - conquanto o fato de que em diversos momentos o Escritório enfatiza a necessidade de uma perspectiva de direitos humanos para a concretização da proteção e que o instituto do refúgio consiste de uma relação intrínseca de fundamento e complementaridade ao campo dos direitos humanos -, essa mesma postura não pôde ser observada no que se refere à sua descrição e análise sobre as condições de vida dos refugiados nos seus países de refúgio. Se, ao tratar da proteção de uma forma geral, a Agência enfoca fortemente a questão dos direitos humanos, seria coerente tratar dessa mesma questão nos países de acolhida-afinal, essa proteção abstrata para a qual se advoga uma perspectiva de direitos humanos somente se concretiza no mundo real dos países de acolhida. Todavia, não é essa a situação observada nas publicações abarcadas por este trabalho, o que leva a um novo questionamento: por que há essa distinção em relação à forma como essa organização se expressa em relação à mencionada vinculação?

\section{O papel da política internacional}

Uma resposta a essa pergunta poderia relacionar-se às situações concretas com as quais o ACNUR tem que lidar. Embora reconheça o fundamento de direitos humanos intrínseco à proteção, esta somente se concretiza dentro de cada 
Estado. O Escritório tem que lidar com as diferenças sociais, culturais, econômicas, jurídicas e normativas que cada um desses contextos representa. Dessa forma, seria possível afirmar que a omissão em invocar uma noção de "direitos humanos" para a proteção se basearia no fato de que existe a possibilidade de que o país em questão não reconheça esses direitos sob a mesma perspectiva da Agência. Entretanto, essa justificativa é desconstruída considerando, em conjunto, alguns comentários sobre os países aqui tratados: 1) todos os três países são signatários da Convenção de 1951, que referencia a Declaração Universal de Direitos Humanos como um de seus fundamentos ${ }^{12} ; 2$ ) os três países são signatários dos mais importantes instrumentos internacionais de direitos humanos - o Pacto Internacional de Direitos Civis e Políticos e o Pacto Internacional de Direitos Econômicos, Sociais e Culturais, de 1966; 3) no caso da Alemanha, trata-se de um país completamente integrado ao regime internacional dos direitos humanos, um país ocidental, que compartilha a mesma ideia de direitos humanos propagada pelo ACNUR, porém, mesmo em tais publicações não se dá maior destaque à questão dos direitos humanos para a proteção.

Embora o estudo não seja definitivo, dada a limitação de documentos analisados e a complexidade de aspectos da proteção internacional e da atuação do ACNUR dentro desse regime, o que se observa remete a uma situação na qual esse organismo se exime de invocar a ideia de direitos humanos para a concretização da proteção nos países de refúgio, em contraposição à sua própria argumentação de que esse é um aspecto essencial desse arranjo internacional. Acredita-se que a ausência de referências aos direitos humanos nas análises da situação dos refugiados nos países de acolhida ultrapassa um simples descompasso entre o ACNUR e o país no que toca à compreensão da noção de direitos humanos. Sem dúvida, a configuração do sistema internacional - baseada no Estado soberano - exerce uma força fundamental na forma como o Escritório vem tratando essa questão.

Nesse sentido, é necessário atentar para um fator central no contexto considerado: a política internacional. Observando-se a emergência do regime internacional dos refugiados é possível inferir que foi uma escolha política que levou à criação desse arranjo internacional, e é numa esfera altamente politizada em que interesses políticos moldam a compreensão dos fatos e as atitudes então derivadas - que a proteção ao refugiado se concretiza. Assim, procede a afirmação (Betts 2009) de que os movimentos de refugiados são inerentemente políticos (envolvendo interesses concorrentes e direitos de cidadãos e não cidadãos).

Um aspecto fundamental da política internacional relacionada ao refúgio é destacado por Loescher (2003), ao afirmar que o ACNUR mantém um arriscado equilíbrio entre a proteção aos refugiados e as prerrogativas e interesses dos Estados,

12 Embora se saiba que a adoção de instrumentos internacionais de direitos humanos não seja suficiente para estabelecermos afirmações definitivas sobre o entendimento de um determinado país sobre a questão, acreditamos ser esse um importante elemento para se entender sua postura dentro do contexto aqui apresentado. 
dependendo dos governos soberanos de acolhida para o acesso e a ordem no seu ambiente operacional. Similarmente, Chimni (1998) sustenta que toda abordagem referente aos refugiados tem que lidar com a tensão entre a prerrogativa dos Estados soberanos de especificar as regras de admissão e as necessidades de pessoas em risco. Malkki (1995) enfatiza que a preponderância da preocupação com a soberania estatal traz consequências negativas para a proteção, como a naturalização e a razoabilidade do fechamento de fronteiras ao refúgio e a necessidade de controle do movimento de pessoas que estão "fora de seus lugares".

Embora pareça evidente o fato de que a política internacional é um fator altamente influenciador e que constrange os desenvolvimentos no campo do regime internacional analisado, esse é um aspecto frequentemente negligenciado pelos estudiosos da temática, como apontam diversos autores (Betts e Loescher 2011; Haddad 2008; Scalettaris 2007). Comumente se identificam os interesses estatais e a ideia de soberania como fatores essenciais para os rumos da proteção internacional à pessoa; entretanto, pouco se demonstra como agem e em qual medida. A análise apresentada sobre as publicações do ACNUR fornece subsídios interessantes para se enfocar a questão e discutir alguns aspectos envolvidos pela problemática.

Como afirmado, o ACNUR tem sempre, em sua atuação, que buscar um equilíbrio entre a proteção ao refugiado e os interesses do país de acolhida. As publicações da Agência analisadas demonstram uma negligência em relação ao signo dos "direitos humanos", em contraposição não apenas à defesa do Escritório da relevância da questão, como também, e principalmente, à realidade - a existência de violaçôes de direitos humanos dos refugiados nos países de acolhida. Acreditase que uma questão central para o entendimento da ausência da ideia de direitos humanos nessas publicações se relaciona a esse equilíbrio necessário à sua atuação e ao papel dos direitos humanos na ordem internacional.

Depois da II Guerra Mundial se formou um consenso, demonstrado na Declaração Universal de 1948, de que os direitos dos indivíduos eram tema de interesse da sociedade internacional (Simmons 2009). Gradualmente, as normas internacionais de direitos humanos tornaram-se amplamente aceitas pelos Estados e entendidas como imperativas, conquanto a falta de mecanismos de enforcement e a existência de interesses nacionais que moldam a forma como os países tratam as questôes de direitos humanos em seu próprio território (Donnelly 2003). Tal força normativa faz com que os Estados, mesmo quando indispostos a traduzir a interdependência moral refletida na ideia de direitos humanos em ações, não estejam dispostos a tratar as práticas nacionais de direitos humanos como questão independente da observação e avaliação internacional. Nesse sentido, a ampla adoção de instrumentos de direitos humanos reflete o alinhamento das preferências dos Estados ao conteúdo dos tratados internacionais que versam sobre a temática (Simmons 2009) e a concordância a respeito da sua relevância para uma governança adequada da questão. 
Por outro lado, embora seja amplamente aceita a relação entre direitos humanos e refúgio, ainda não é consensual a compreensão de que os primeiros devem constituir parâmetro para a determinação do status de refugiado (Foster 2007). Apesar dos mais de 60 anos de existência do regime internacional dos refugiados fundado na Convenção de 1951, ainda é amplo o debate a respeito dessa vinculação e, frequentemente, tenta-se desconstruir tal relação visando exatamente a evitar o imperativo moral que os direitos humanos representam. Acredita-se ser possível que esse também constitua o fator central para a postura do ACNUR de evitar tratar das condições dos refugiados em seus países de acolhida em termos de direitos humanos, apesar da manifesta defesa pela Agência da existência desse vínculo.

Devido ao reconhecimento de que os direitos humanos representam normas amplamente aceitas que devem ser observadas pelos Estados é que invocar os direitos humanos nas suas publicações desconstruiria o equilíbrio necessário ao trabalho do ACNUR nos países de acolhida. Falar em direitos humanos significa recorrer a um imperativo mais forte que o humanitarismo comumente declarado como responsável pela formulação do arranjo internacional para a questão dos refugiados. E a parcimônia tem sido uma das estratégias para implementação das políticas do ACNUR para a proteção aos refugiados. Desse modo, mesmo a forma como essa Agência se expressa em relação à vida dos refugiados nos países de refúgio é influenciada pela política internacional.

\section{Considerações finais}

Os interesses dos Estados soberanos, mutáveis como são, determinam, não obstante os compromissos assumidos internacionalmente, os rumos da proteção aos refugiados. Haddad (2008) aponta, de forma pertinente, que moralmente falando as demandas humanitárias do oferecimento de proteção internacional ao refugiado devem superar quaisquer preocupações, mas a realidade mostra que é impossível separar o ético do político no mundo moderno de relações interestatais. Assim, a falha em responder adequadamente aos fluxos de refugiados deve-se, em larga medida, à natureza política e internacional do problema, sendo essa refletida em todos os aspectos que envolvem a temática. É possível, então, perceber que até mesmo as publicações que visam a evidenciar a questão e garantir apoio, para fornecer uma proteção adequada aos refugiados, são permeadas por consideraçōes de política internacional. Tais considerações, portanto, moldam a forma como o ACNUR se manifesta em relação às condições de vida dos refugiados nos países de acolhida - obscurecendo seu entendimento sobre a importância das questóes de direitos humanos para a proteção dos refugiados e, consequentemente, legitimando, de alguma forma, o não reconhecimento de sua relevância.

A proteção efetiva dos refugiados apenas é possível a partir da compreensão de seus fundamentos e de todos os fatores intervenientes. Indubitavelmente, 
as dinâmicas da política internacional representam um fator essencial no contexto apresentado e, por esse motivo, é necessário suprir as lacunas de pesquisa na área, deixando de somente apontar questôes e passando a analisá-las. Esse é um dos caminhos possíveis para a superação da tão mencionada "crise da proteção internacional" e o estabelecimento de um espaço efetivo de proteção para os refugiados.

\section{Referências bibliográficas}

ACNUR; ONU. (2002). Direitos humanos e refugiados. Lisboa: ACNUR/ONU. Publicado em [http://www.gddc.pt/direitos-humanos/Ficha_Informativa_20.pdf]. Disponibilidade: 24 set. 2012.

BARRETO, L P T F. Das diferenças entre os institutos jurídicos do asilo e do refúgio. Brasília: IMDH, 2006. Disponível em: <http://www.migrante.org.br/textoseartigos.htm>. Acesso em: 20 dez. 2012.

BETTS, Alexander. (2009). Forced migration and global politics. Chichester: Wiley-Blackwell.

BETTS, Alexander; LOESCHER, Gil. Refugees in International Relations. (2011). In: BETTS, Alexander; LOESCHER, Gil (eds.). Refugees in international relations. New York: Oxford University Press. p. 1-27.

CHIMNI, B. S. (1998). The Geopolitics of refugee studies: a view from the south. Journal of Refugee Studies. Vol. 11, No 4, 1998, p. 350-374. Publicado em [http://jrs.oxfordjournals.org/ content/11/4/350.2.full.pdf]. Disponibilidade: 24 set. 2012.

COMPARATO, Fábio Konder. A Afirmação histórica dos direitos humanos. São Paulo: Saraiva, 2010.

DONNELLY, Jack. (2003). Universal human rights in theory and practice. New York: Cornell University Press.

FOSTER, Michelle. (2007). International refugee law and socio-economic rights: refugee from deprivation. New York: Cambridge University Press.

HADDAD, Emma. (2008). The Refugee in international society: between sovereigns. New York: Cambridge University Press.

JUBILUT, Liliana. (2007). O Direito internacional dos refugiados e sua aplicação no ordenamento jurídico brasileiro. São Paulo: Método.

MALKKI, Lisa. (1995). Refugees and exile: from 'refugee studies' to the national order of things. Annual Review of Anthropology. Vol. 24, 1995, p. 495-523. Publicado em [http://www. annualreviews.org/doi/pdf/10.1146/annurev.an.24.100195.002431]. Disponibilidade 24 set. 2012.

ONU. (1951). Convenção Relativa ao Estatuto do Refugiado. Publicado em [http://www.acnur. org/t3/portugues/recursos/documentos/]. Disponibilidade: 24 set. 2012.

RUBIO, David Sanchéz. (2010). Fazendo e desfazendo direitos humanos. Santa Cruz do Sul: Edunisc. 
SCALETTARIS, Giulia. (2007). Refugee studies and the international refugee regime: a reflection on a desirable separation. Refugee Survey Quarterly, Vol. 26, No 3, 2007, p. 36-50. Publicado em [http://rsq.oxfordjournals.org/content/26/3/36.full.pdf+html]. Disponibilidade: 24 set. 2012.

SIMMONS, Beth. (2009). Mobilizing for human rights: international law in domestic politics. Cambridge: Cambridge University Press.

UNHCR. (1992). Handbook on procedures and criteria for determining refugee status under the 1951 Convention and the 1967 Protocol relating to the status of refugee. Geneva. Publicado em [http://www.unhcr.org/3d58e13b4.html]. Disponibilidade: 24 set. 2012.

(1995). Human rights and refugee protection (RLD 5). Geneva. Publicado em [http://www.unhcr.org/3ae6bd900.pdf]. Disponibilidade: 24 set. 2012.

. (1997). UNHCR and Human Rights: a policy paper resulting from deliberations in the Policy Committee on the basis of a paper prepared by the Division of International Protection. Geneva. Publicado em [http://www.unhcr.org/refworld/docid/3ae6b332c.html]. Disponibilidade: 24 set. 2012.

. (2001a). Global Appeal 2002. Geneva. Publicado em [http://www.unhcr.org/4a0bdd2d6. html]. Disponibilidade: 24 set. 2012.

. (2001b). Global Consultations: update 31 january 2001. Publicado em [http://www. unhcr.org/3d6c8c504.html]. Disponibilidade: 24 set. 2012.

. (2002a). Statistical Yearbook 2001: trends in displacement, protection and solutions. Geneva. Publicado em [http://www.unhcr.org/4a02e3406.html]. Disponibilidade: 24 set. 2012.

(2002b). Global Appeal 2003. Geneva. Publicado em [http://www.unhcr.org/4a0bd6cc6. html]. Disponibilidade: 24 set. 2012.

. (2003). Global Appeal 2004. Geneva. Publicado em [http://www.unhcr.org/4a0bcb826. html]. Disponibilidade: 24 set. 2012.

. (2004a). Statistical Yearbook 2002: trends in displacement, protection and solutions. Geneva. Publicado em [http://www.unhcr.org/4a07e87d6.html]. Disponibilidade: 24 set. 2012.

. (2004b). Global Appeal 2005. Geneva. Publicado em [http://www.unhcr.org/4a0ae8276. html]. Disponibilidade: 24 set. 2012.

(2005a). Handbook for planning and implementing development assistance for refugees (DAR) programmes. Mod. I. Geneva. Publicado em [http://www.unhcr.org/refworld/ docid/428076704.html]. Disponibilidade: 24 set. 2012.

. (2005b). Refugee status determination: identifying who is a refugee. Self-study module 2. Geneva. Publicado em [http://www.unhcr.org/refworld/docid/43141f5d4.html]. Disponibilidade: 24 set. 2012.

. (2005c). Statistical Yearbook 2003: trends in displacement, protection and solutions. Geneva. Publicado em [http://www.unhcr.org/42aff7e84.html]. Disponibilidade: 24 set. 2012.

. (2005d). Global Appeal 2006. Geneva. Publicado em [http://www.unhcr.org/4a0ad61f6. html]. Disponibilidade: 24 set. 2012. 
(2006a). Statistical Yearbook 2004: trends in displacement, protection and solutions. Geneva. Publicado em [http://www.unhcr.org/44e96c842.html]. Disponibilidade: 24 set. 2012.

. (2006b). Global Appeal 2007. Geneva. Publicado em [http://www.unhcr.org/4a0a900f6. html]. Disponibilidade: 24 set. 2012.

. (2007a). Statistical Yearbook 2005: trends in displacement, protection and solutions. Geneva. Publicado em [http://www.unhcr.org/464478a72.html]. Disponibilidade: 24 set. 2012.

. (2007b). Statistical Yearbook 2006: trends in displacement, protection and solutions. Geneva. Publicado em [http://www.unhcr.org/478cda572.html]. Disponibilidade: 24 set. 2012.

. (2007c). Global Appeal 2008-2009. Geneva. Publicado em [http://www.unhcr.org/ ga08/index.html]. Disponibilidade: 24 set. 2012.

. (2008a). Statistical Yearbook 2007: trends in displacement, protection and solutions. Geneva. Publicado em [http://www.unhcr.org/4981b19d2.html]. Disponibilidade: 24 set. 2012.

. (2008b). Global Appeal 2009 (Update). Geneva. Publicado em [http://www.unhcr.org/ ga09/index.html]. Disponibilidade: 24 set. 2012.

. (2009a). Statistical Yearbook 2008: trends in displacement, protection and solutions. Geneva. Publicado em [http://www.unhcr.org/4bcc5bb79.html]. Disponibilidade: 24 set. 2012.

(2009b). Global Appeal 2010-2011. Geneva. Publicado em [http://www.unhcr.org/ ga10/index.html\#/home]. Disponibilidade: 24 set. 2012.

. (2010a). Statistical Yearbook 2009: trends in displacement, protection and solutions. Geneva. Publicado em [http://www.unhcr.org/4ce532ff9.html]. Disponibilidade: 24 set. 2012.

. (2010b). Global Appeal 2011 (Update). Geneva. Publicado em [http://www.unhcr.org/ ga11/index.html\#/home]. Disponibilidade: 24 set. 2012.

. (2011). Statistical Yearbook 2010: trends in displacement, protection and solutions. Geneva. Publicado em [http://www.unhcr.org/4ef9cc9c9.html]. Disponibilidade: 24 set. 2012.

Recebido em 24 de dezembro de 2012 Aprovado em 5 de fevereiro de 2013

\section{Resumo}

A literatura sobre refugiados tem explorado a vinculação entre refúgio e direitos humanos nos países de acolhida - aspecto fundamental do regime internacional dos refugiados - em uma perspectiva predominantemente descritiva. Ressaltando a necessidade de abordagens analíticas sobre a temática, este trabalho analisa como o Alto Comissariado das Nações Unidas para os Refugiados (ACNUR) tem se manifestado no que concerne aos direitos humanos dos refugiados nos países de acolhida, apontando a influência da política internacional nesse contexto. Entendese que, uma vez compreendido o regime em sua relação com os direitos humanos, estes devem representar o parâmetro para se analisar a forma como ocorre a concretização da proteção internacional.

Palavras-chave: Alto Comissariado das Nações Unidas para os Refugiados (ACNUR); direitos humanos; política internacional; refugiados. 


\section{Abstract}

The literature about refugees has explored the link between refugees and human rights in the host countries - a fundamental aspect of the international refugee regime - in a predominantly descriptive perspective. Highlighting the importance of analytical approaches about the theme, this paper analyzes how the United Nations High Commissioner for Refugees (UNHCR) has expressed itself with regard to the refugee human rights in their host countries, signalizing the influence of the international politics in this context. Once understood the regime and its relation to the human rights, it is believed that the latter represents the parameter to analyze the way the international protection is provided.

Keywords: United Nations High Commissioner for Refugees (UNHCR); human rights; international politics; refugees. 